\section{Microhardness homogeneity of RBCs light-cured with a multiple-peak LED and surface characterization after wear}

\author{
Beatriz Ometto Sahadi (D1, Gabriel Nima (D1, Carolina Bosso André (D) 2 , \\ Maicon Sebold (D1, Regina Guenka Palma-Dibb [13 3 Juliana Jendiroba \\ Faraoni (D), Marcelo Giannini (D)1.
}

\begin{abstract}
This in vitro study evaluated the effect of the beam homogeneity of a multiple-peak light-curing unit on the surface microhardness and the effect of toothbrushing wear on the microhardness, surface roughness, roughness profile, volume loss, and gloss retention of incremental and bulk-fill resinbased composites (RBCs). A LED light-curing unit (VALO) with four LEDs at the tip end $(405,445,465 \mathrm{~A}$, and 465B nm emission peak) was used according to each manufacturer-recommended time to obtain disks $(n=10)$ of six RBCs: Estelite Sigma Quick, Charisma Classic, Tetric EvoCeram Bulk Fill, Filtek Z250, Filtek Supreme Ultra, and Filtek Bulk Fill. Microhardness values were obtained according to each LED positioning of the light-curing unit on the top surface of the RBCs and were analyzed before and after toothbrushing regarding microhardness, surface roughness, roughness profile, volume loss, and gloss retention. Microhardness was considered homogeneous on the top surface regardless of the type of $\mathrm{RBC}$ or wavelength tested $(p>0.05)$. Overall, toothbrushing did not reduce the microhardness of the RBCs but influenced the gloss values for most RBCs $(p<0.001)$. Charisma Classic presented the greatest surface roughness and roughness profile after toothbrushing $(p<0.05)$. Volume loss did not differ among RBCs $(p>0.05)$. In conclusion, different wavelengths of the LED did not affect the top surface microhardness, regardless of the RBCs tested; and bulk-fill composites presented similar surface changes (microhardness, surface roughness, roughness profile, volume loss, and gloss retention) when compared to conventional composites after toothbrushing.
\end{abstract}

1 Department of Restorative Dentistry, Piracicaba Dental School, University of Campinas, Piracicaba, Brazil.

2 Department of Restorative Dentistry, School of Dentistry, Federal University of Minas Gerais, Belo Horizonte, Brazil.

3 Department of Restorative Dentistry, Ribeirão Preto School of Dentistry, University of São Paulo, Ribeirão Preto, Brazil.

Correspondence: Carolina Bosso André, PhD.; Department of Restorative Dentistry Operative Dentistry Division; Dental School Federal University of Minas Gerais; Av. Presidente Antonio Carlos, 6627 - Pampulha; Belo Horizonte, MG, Brazil; Zip Code: 31270901; Phone: 55313409243 e-mail: carolina.bosso@gmail.com

Key Words: Resin composite, bulkfill composite, toothbrushing, dental light-curing, microhardness.

\title{
Introduction
}

Currently, resin-based composites are widely used in restorative dentistry, since they have evolved significantly regarding filler content, resin matrix, and initiator system technology throughout the years (1). These characteristics have improved the polymerization process and the mechanical properties of composites, leading to improved longevity of direct restorations $(2,3,4)$. Composite materials should resist to the oral environment challenges, as the degradation caused by salivary and biofilm produced enzymes and acids (5), $\mathrm{pH}$ variation, due to consumption of acidic beverages or foods (6), abrasion and occlusal load (7).

Recurrent caries and fractures are considered the main reasons for composite restorations failure. On the other hand, esthetic significantly influence the replacement of composite restorations in anterior teeth (2). Color mismatch and discoloration, surface or marginal staining, gloss and anatomical loss, increase in surface roughness or marginal breakdowns are examples of esthetic concerns and criteria used to replace anterior composite restorations $(2,8,9)$.

The amount of restorative material loss depends on the features of resin composites, such as filler particle size, shape, and content, organic matrix composition, and polymerization dynamics (10). Handin-hand with material-dependent characteristics, the type of toothpaste, and parameters related to the act of toothbrushing will also determine the abrasiveness potential of tooth cleaning, as well as the degree of wear caused by brushing abrasion over time (11). The composite surface changes following toothbrushing are easily observed, and one of the factors that might affect the restorative material is the light-curing quality (12). Similar to composites, light-curing units (LCUs) have also evolved significantly, and the contemporary light-emitting diode (LED) units can have a single-peak (emitting blue light only) or multiple-peak (emitting a combination of both violet and blue light) wavelength. 
The effects of both types of LED units (single or multiple-peak), photoinitiators, and heterogeneous light distribution on gloss, roughness, wear-resistance, and other physical properties of resin composites have been discussed in many articles since these factors are believed to predict the clinical behavior of restorations (13). Nonetheless, surface gloss and smoothness are also involved in the esthetic appearance of composite restorations, and therefore these properties may also influence the longevity of restorative procedures (8).

This study aimed to evaluate the effect of the beam homogeneity of a multiple-peak LCU on the surface microhardness, and the effect of simulated toothbrushing on the microhardness, surface roughness, roughness profile, volume loss, and gloss retention of resin-based incremental and bulk-fill composites (RBC). The null hypotheses were that (1) different wavelengths emitted by the LED lightcuring unit would not affect the top microhardness homogeneity of RBCs at different surface locations; (2) simulated toothbrushing wear would not affect the microhardness of RBCs of $405 \mathrm{~nm}$ wavelength position compared to $465 \mathrm{~nm}$. (3) simulated toothbrushing wear would not affect the surface roughness and roughness profile; (4) simulated toothbrushing wear would not affect the volume loss of the tested $\mathrm{RBC}$, and (5) toothbrushing would not affect the gloss retention of RBCs.

\section{Materials and methods}

Specimen preparation, LCU characterization, and experimental groups

A commercial multiple-peak LED LCU (Valo Cordless, Ultradent Products, Inc., South Jordan, UT, USA; serial \#MFG3277-5) presenting different emission peaks were used to investigate top surface changes of different RBCs after simulated toothbrushing. The LCU delivered a radiant emittance of 953 $\mathrm{mW} / \mathrm{cm}^{2}$ and an emission spectrum ranging from $380 \mathrm{~nm}$ to $490 \mathrm{~nm}$, with three emission peaks (at 405 $\mathrm{nm}, 445 \mathrm{~nm}$, and $465 \mathrm{~nm}$ ). This LCU presents four LED chips at the tip end, including two LEDs with an emission peak at $465 \mathrm{~nm}$. The emission spectrum for the LCU is shown in Figure 1. The output of the LCU was measured using a 6-inch integrating sphere (Labsphere, North Sutton, NH, USA) attached to a fiberoptic spectrometer (USB-4000, Ocean Optics, Dunedin, IL, USA).

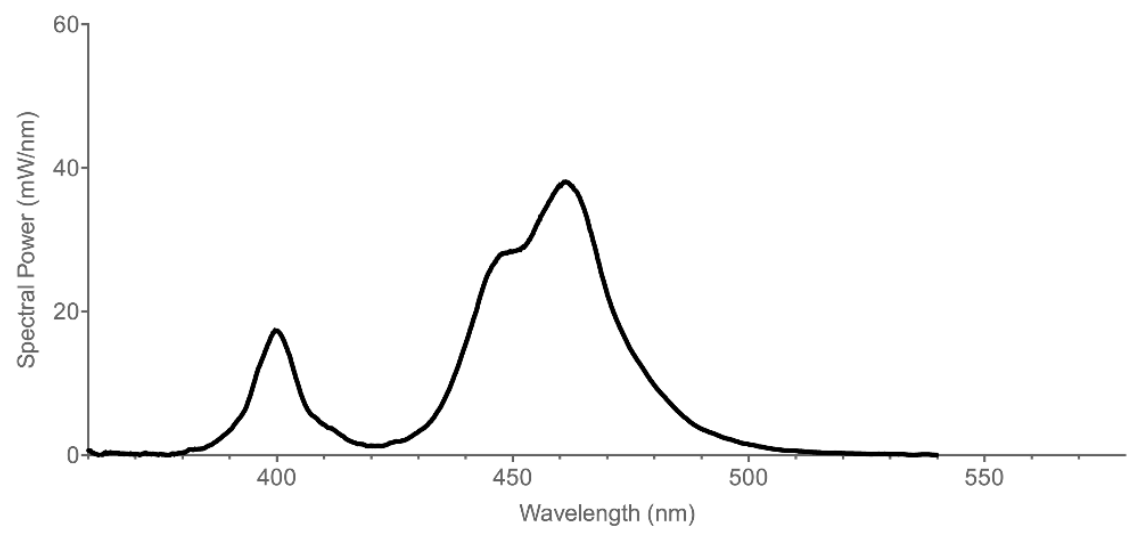

Figure 1. Emission spectrum of the Valo LCU.

Six RBCs were tested in this in vitro study, four incremental composites (Estelite Sigma Quick, Charisma Classic, Filtek Z250, and Filtek Supreme Ultra) and two bulk-fill composites (Tetric EvoCeram Bulk Fill, and Filtek Bulk Fill Posterior). Their composition, as provided by the manufacturers, and their batch numbers are reported in Table 1. Polyvinyl siloxane impression material molds (Putty Softy, 3M Oral Care, St Paul, MN, USA) were used for making composite disk-shaped samples from each RBC $(\mathrm{n}=$ 10), with $2 \mathrm{~mm}$ thickness and $10 \mathrm{~mm}$ diameter. The composites were placed inside the molds in a single increment. A mylar strip was placed on the top of the uncured composite, followed by light-curing according to the recommended time of each RBC manufacturer, with the LCU light tip in contact with the mylar strip. After light-curing, the composite disks were removed from the molds, and the bottom composite surface was marked with a notch to indicate the position of each LED of the LCU at the top surface, where the microhardness measurements were performed to analyze the influence of LED chips on this property. The top surface of the composite disks that received light was slightly wet-polished with SiC sandpaper (600-grit, 3M of Brazil, Sumaré, SP, Brazil) for 10 seconds to simulate the clinical 
finishing procedures (12). The specimens were then stored in deionized water for 24 hours at room temperature.

Table 1. RBCs manufacturers, compositions, shade, and lot numbers.

\begin{tabular}{|c|c|c|c|c|}
\hline $\begin{array}{l}\text { Resin Composites } \\
\text { (manufacturer) }\end{array}$ & Type (shade) & Composition & $\begin{array}{l}\text { Exposure } \\
\text { time }\end{array}$ & $\begin{array}{c}\text { Lot } \\
\text { number }\end{array}$ \\
\hline $\begin{array}{l}\text { Charisma Classic } \\
\text { (Kulzer GmbH, } \\
\text { Hanau, Germany) }\end{array}$ & $\begin{array}{l}\text { Incremental } \\
\text { Microhybrid } \\
\text { (A2) }\end{array}$ & $\begin{array}{l}\text { Bis-GMA, TEGDMA. } \\
\text { Filler load: } 61 \% \text { by volume ( } 60 \% \text { inorganic filler } \\
\text { by volume and pre-polymerized filler), particle } \\
\text { size of } 0.005-10 \mu \mathrm{m} \text {, barium aluminum fluoride } \\
\text { glass. }\end{array}$ & $20 \mathrm{~s}$ & $010054 \mathrm{~A}$ \\
\hline $\begin{array}{l}\text { Estelite Sigma } \\
\text { Quick (Tokuyama } \\
\text { Dental, Japan) }\end{array}$ & $\begin{array}{l}\text { Incremental } \\
\text { Supra-nano } \\
\text { filled } \\
\text { (A1) }\end{array}$ & $\begin{array}{l}\text { Bis-GMA, TEGDMA, Bisphenol A di(hydroxy } \\
\text { propoxy). } \\
\text { Filer Load: } 82 \% \text { by weight ( } 71 \% \text { by volume) of } \\
\text { silica-zirconia filler and composite filler, } \\
\text { spherical submicron filler (mean particle size } \\
200 \mathrm{~nm} \text {, particle size range: } 100 \text { to } 300 \mathrm{~nm} \text { ). }\end{array}$ & $10 \mathrm{~s}$ & W936 \\
\hline $\begin{array}{l}\text { Filtek Z250 (3M } \\
\text { Oral Care, St. Paul, } \\
\text { USA) }\end{array}$ & $\begin{array}{l}\text { Incremental } \\
\text { Microhybrid } \\
\text { (A2) }\end{array}$ & $\begin{array}{l}\text { Bis-EMA, UDMA, Bis-GMA, TEGDMA. } \\
\text { Filer load: } 67.8 \% \text { inorganic filler by volume, } \\
\text { silica-zirconia. Silane Treated Ceramic } 75-85 \% \\
\text { by weight. The particle size distribution is } 0.01 \\
\mu \mathrm{m} \text { to } 3.5 \mu \mathrm{m} \text { with an average particle size of } \\
0.6 \mu \mathrm{m} \text {. }\end{array}$ & $20 \mathrm{~s}$ & N760409 \\
\hline $\begin{array}{l}\text { Filtek Supreme } \\
\text { Ultra (3M Oral } \\
\text { Care, St. Paul, } \\
\text { USA) }\end{array}$ & $\begin{array}{l}\text { Incremental } \\
\text { Nanofilled } \\
\text { (A2 Body) }\end{array}$ & $\begin{array}{l}\text { Bis-GMA, Bis-EMA, UDMA, TEGDMA, PEGDMA. } \\
\text { Filer load: } 78.5 \% \text { by weight ( } 63.3 \% \text { by volume). } \\
\text { The fillers are a combination of non- } \\
\text { agglomerated/non-aggregated zirconia/silica } \\
\text { cluster filler (comprised of } 20 \mathrm{~nm} \text { silica and } 4 \text { to } \\
11 \mathrm{~nm} \text { zirconia particles). The particle size is } 0.6 \\
\text { to } 20 \mu \mathrm{m} \text {. }\end{array}$ & $20 \mathrm{~s}$ & 368525 \\
\hline $\begin{array}{l}\text { Tetric EvoCeram } \\
\text { Bulk Fill (Ivoclar } \\
\text { Vivadent, Schaan, } \\
\text { Liechtenstein) }\end{array}$ & $\begin{array}{l}\text { Bulk-fill } \\
\text { Nanohybrid } \\
\text { (A2) }\end{array}$ & $\begin{array}{l}\text { Dimethacrylates, Bis-GMA, Bis-EMA, UDMA. } \\
\text { Filer load: } 76-77 \% \text { by weight or } 53-54 \% \text { by } \\
\text { volume of inorganic fillers. The fillers contain } \\
\text { barium glass, ytterbium trifluoride, mixed oxide } \\
\text { and copolymers ( } 79-81 \% \text { ). The particle sizes } \\
\text { range between } 40 \mathrm{~nm} \text { and } 3 \mu \mathrm{m} \text {. }\end{array}$ & $20 \mathrm{~s}$ & S40860 \\
\hline $\begin{array}{l}\text { Filtek Bulk Fill } \\
\text { Posterior (3M Oral } \\
\text { Care, St. Paul, } \\
\text { USA) }\end{array}$ & $\begin{array}{l}\text { Full-body } \\
\text { Bulk-fill } \\
\text { Nanofilled } \\
\text { (A2) }\end{array}$ & $\begin{array}{l}\text { Aromatic UDMA, 1,12-dodecane dimethacrylate, } \\
\text { UDMA, pentanedioic acid, 2,2-dimethyl-4- } \\
\text { methylene-(reaction products with glycidyl } \\
\text { methacrylate), ethyl 4-dimethyl aminobenzoate, } \\
\text { benzotriazole. } \\
\text { Filer load: } 76.5 \% \text { by weight ( } 58.4 \% \text { by volume). } \\
\text { Non-agglomerated/non-aggregated } 20 \mathrm{~nm} \text { silica } \\
\text { filler, a non-agglomerated/non-aggregated } 4 \text { to } \\
11 \mathrm{~nm} \text { zirconia filler, an aggregated } \\
\text { zirconia/silica cluster filler (comprised of } 20 \mathrm{~nm} \\
\text { silica and } 4 \text { to } 11 \mathrm{~nm} \text { zirconia particles) and a } \\
\text { ytterbium trifluoride filler consisting of } \\
\text { agglomerate } 100 \mathrm{~nm} \text { particles, titanium dioxide. }\end{array}$ & $20 \mathrm{~s}$ & N685666 \\
\hline
\end{tabular}

Abbreviations: Bis-GMA: bisphenol-A diglycidyl ether dimethacrylate; TEGDMA: triethyleneglycol dimethacrylate; Bis-EMA6: bisphenol a polyethylene glycol diether dimethacrylate; UDMA: diurethane dimethacrylate; Bis-EMA: ethoxylated bisphenol-A dimethacrylate; PEGDMA: polyethylene glycol dimethacrylate; DDMA: 1,12-dodecane dimethacrylate; DUDMA: diurethane dimethacrylate.

\section{Top surface microhardness and toothbrushing cycling}

In order to obtain Knoop hardness (KHN) values from the top surface of the RBCs according to each LED position (405, 445, 465A and 465B nm irradiation locations), a microhardness tester (Future-Tech FM Corp, Tokyo, Japan), coupled to a software (FM-ARS 9000, Future-Tech FM Corp), was used by 
applying a static load of $50 \mathrm{~g}(0.49 \mathrm{~N})$ for five seconds to each composite surface, following the marked areas of each LCU LED. The results of three indentations were averaged to represent a single microhardness value for each LED region. Each indentation was spaced at $100 \mu \mathrm{m}$ from the other, at the central irradiant spot of each LED, and $3 \mathrm{~mm}$ from the outer surface of the composite disk (Figure 2).
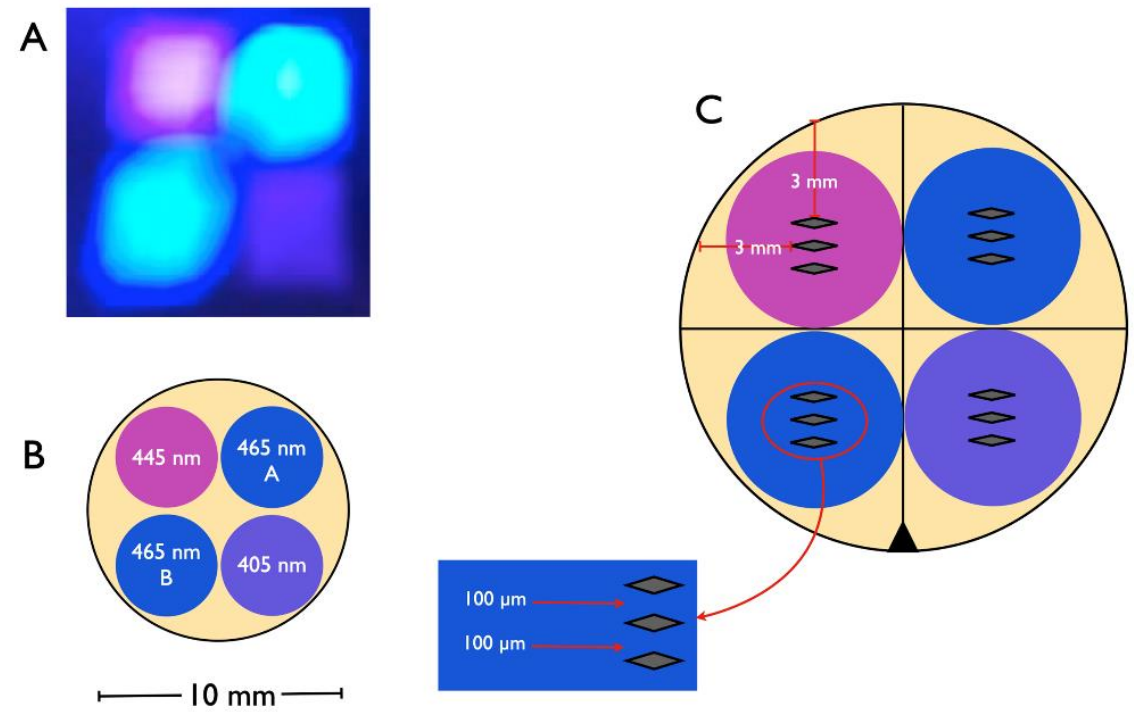

Figure 2. Schematic representation of microhardness indentations in each LED wavelength area on the top surface of RBCs. (A) Identification of each LED position. (B) The corresponding top surface area of each LED wavelength. (C) Indentation distances from each other and the outer surface.

An adhesive tape (Scotch duct tape 471, 3M of Brazil, Sumaré, SP, Brazil) was applied manually on half of the top surface samples, covering $445 \mathrm{~nm}$ and 465B nm irradiation locations. This covered area was defined as the control (unbrushed) for confocal microscopy analysis. Uncovered area of composite disks (405 and 465A irradiation locations) was submitted to 30,000 reciprocal strokes (150 cycles/min) in a toothbrushing simulation machine (Biopdi, São Carlos, SP, Brazil), which corresponded to approximately two years of toothbrushing (14). A load of $200 \mathrm{~g}$ was placed on soft toothbrushes (OralB Indicator 35, Procter \& Gamble, Seropédica, RJ, Brazil). Each disk was covered in toothpaste slurry (Oral-B Pro-Health, Procter \& Gamble), comprising $16 \mathrm{~g}$ of toothpaste in $100 \mathrm{~mL}$ of deionized water.

After simulated toothbrushing wear, the adhesive tape was removed, and the specimens were thoroughly washed and air-dried. A new microhardness was obtained only on the brushed area, which correspond to $405 \mathrm{~nm}$ and $465 \mathrm{~A} \mathrm{~nm}$ irradiation locations. Data fulfilled the parameters for parametric analysis. Surface microhardness of the four LED wavelengths before toothbrushing were analyzed by one-way repeated-measures ANOVA (between-subject factor: LED wavelength). Surface microhardness after toothbrushing was analyzed by two-way repeated-measures ANOVA (between-subject factors: LED wavelength and toothbrushing).

\section{Confocal microscopy analysis}

After toothbrushing, surface roughness $(\mathrm{Sa})$, roughness profile (Rv), and volume loss of each disk were measured using laser confocal microscopy (LEXT 3D Measuring Laser Microscope OLS4000, Olympus Corp., Tokyo, Japan). A 5x objective lens ( 1 x zoom) was used to obtain images (1024 x 1024 pixels, XYZ fast scan) with a $405 \mathrm{~nm}$ laser (Gaussian filter). Also, representative three-dimensional (3D) and twodimensional (2D) images of the surfaces of the composites were obtained to compare the unbrushed with the brushed areas to identify the wear profile of each RBC. The Sa parameter describes the arithmetic height deviation from a mean plane three-dimensionally, which measures surface roughness by detecting the maximum peak to valley heights of a specific surface profile (15). For the calculation of Sa, an area of $2.6 \times 2.6 \mathrm{~mm}$ of each side (unbrushed and brushed) of composite surface were used, regardless of the LED location. An image containing part of the unbrushed side $(0.5 \mathrm{~mm})$ and the brushed side was obtained from each sample to calculate the surface roughness profile and the volume loss (2.6 
$x 2.6 \mathrm{~mm}$ image). The roughness profile (2D) was determined from the largest valley depth deviation from the mean line within a given length of $2.6 \mathrm{~mm}$ (10 readings for each composite disk). In order to calculate the volume loss, a reference plane from the top of the unbrushed area was defined, and the software calculated the volume loss located below this reference. Confocal microscopy data did not follow the assumptions for a parametric test (normality and homoscedasticity). Sa was analyzed by Kruskal-Wallis' one-way analysis of variance on ranks followed by Student-Newman-Keuls and Wilcoxon signed rank test. Roughness profile and volume loss were analyzed by Kruskal-Wallis one-way analysis of variance on ranks followed by Student-Newman-Keuls. The 2D and 3D images were analyzed qualitatively.

\section{Gloss retention}

The top surface gloss (gloss units - GU) of the RBCs was measured with the Novo-Curve glossmeter (Rhopoint Instruments Ltd, Hastings, Sussex, UK) at a $60^{\circ}$ angle of illumination. The device has a $4.5 \mathrm{~mm}$ aperture, and it was calibrated $(93.3 \mathrm{GU})$ with a plate provided by the manufacturer before the measurements. Two gloss measurements were performed on each area (unbrushed and toothbrushed), and an average of the two measurements was obtained. The results for each RBC were expressed in GU. The toothbrushed side was compared to the unbrushed side that corresponded to the simulated clinical finishing procedure. Gloss was transformed by square root to fulfill the parameters for parametric analysis and analyzed by two-way mixed ANOVA (between-subject factor: RBC; within-subject factor: toothbrushing).

\section{RESULTS}

\section{Microhardness}

Table 2 depicts polished surface microhardness means of RBCs for each corresponding LED wavelength. The "LED wavelength" $(p=0.010)$ and "RBCs" $(p<0.001)$ factors significantly influenced the microhardness results. No significant difference was observed among the four LED wavelength positions (at $405,445,465 \mathrm{~A}$ and $465 \mathrm{Bm}$ ), regardless of the type of RBC tested. For this reason, the light-curing beam was considered homogenous.

Table 2. Mean (SD) of RBCs top microhardness for each LED wavelength.

\begin{tabular}{|c|c|c|c|c|c|}
\hline \multirow{2}{*}{ Surface } & \multirow{2}{*}{$\mathrm{RBC}$} & \multicolumn{4}{|c|}{ Wavelength } \\
\hline & & $405 \mathrm{~nm}$ & $445 \mathrm{~nm}$ & 465A nm & 465B nm \\
\hline \multirow{7}{*}{ Top } & Estelite Sigma Quick & 55.7 (7.1) A & 56.3 (7.6) A & $56.0(6.5) \mathrm{A}$ & 56.5 (8.7) A \\
\hline & Charisma Classic & $66.0(8.8) \mathrm{A}$ & $69.0(7.0) \mathrm{A}$ & 70.0 (7.8) A & $68.9(9.9) \mathrm{A}$ \\
\hline & Filtek Z250 & 75.1 (9.3) A & $74.1(8.8) \mathrm{A}$ & $77.0(10.8) \mathrm{A}$ & 73.3 (7.2) A \\
\hline & & & & & \\
\hline & Filtek Supreme Ultra & $71.3(6.3) \mathrm{A}$ & 70.3 (7.8) A & 73.0 (7.4) A & 75.7 (4.6) A \\
\hline & $\begin{array}{l}\text { Tetric EvoCeram Bulk } \\
\text { Fill }\end{array}$ & 53.9 (6.4) A & 52.5 (7.0) A & 55.8 (3.5) A & $55.9(6.0) \mathrm{A}$ \\
\hline & $\begin{array}{l}\text { Filtek Bulk Fill } \\
\text { Posterior }\end{array}$ & 64.9 (8.8) A & $67.1(4.7) \mathrm{A}$ & 69.4 (7.6) A & 66.8 (7.9) A \\
\hline
\end{tabular}

$\overline{\text { Means followed by different letters indicate a significant difference (uppercase letters compare wavelength }}$ within the same RBC) by one-way repeated-measures ANOVA and post-hoc Tukey's test ( $<<0.05)$.

Microhardness means (SD) for the $405 \mathrm{~nm}$ and 465A nm wavelength-corresponding areas submitted to toothbrushing wear is reported in Table 3. The factors interaction between "RBCs" and "brushing" $(p<0.001)$, "RBCs" and "LED wavelength" ( $p=0.050)$, and "brushing" and "LED wavelength" $(p=0.013)$ significantly influenced the microhardness results. Only Filtek Z250 presented a reduction in microhardness values for both $405 \mathrm{~nm}$ and $465 \mathrm{~A} \mathrm{~nm}$ wavelengths after toothbrushing. Filtek Bulk Fill Posterior exhibited statistical difference comparing $405 \mathrm{~nm}$ with $465 \mathrm{~A} \mathrm{~nm}$ wavelengths for both unbrushed and toothbrushed sides and Charisma Classic at the unbrushed side. However, for both composites, the $405 \mathrm{~nm}$ presented a close numerical value to $465 \mathrm{~B} \mathrm{~nm}$ in the unbrushed region (Table 
2). For the brushed side of Filtek Bulk Fill Posterior, the $405 \mathrm{~nm}$ wavelength presented a close numerical value to the 465B nm wavelength (Table 2), although no statistical analysis was performed.

Table 3. Mean (SD) of RBCs top microhardness, before and after brushing, for both uncovered LED wavelengths.

\begin{tabular}{|c|c|c|c|}
\hline Wavelength & $\mathrm{RBC}$ & Unbrushed & Brushed \\
\hline \multirow{6}{*}{$405 \mathrm{~nm}$} & Estelite Sigma Quick & $55.7(7.1) \mathrm{A}$ & $57.1(5.9) \mathrm{A}$ \\
\hline & Charisma Classic & $66.0(8.8) \mathrm{A}^{*}$ & $69.2(4.8) \mathrm{A}$ \\
\hline & Filtek Z250 & 75.1 (9.3) A & $58.7(4.6) \mathrm{B}$ \\
\hline & Filtek Supreme Ultra & $71.3(6.3) \mathrm{B}$ & 78.3 (4.2) A \\
\hline & Tetric EvoCeram Bulk Fill & $53.9(6.4) \mathrm{B}$ & $58.7(4.6) \mathrm{A}$ \\
\hline & Filtek Bulk Fill Posterior & $64.9(8.8) \mathrm{A}^{*}$ & $66.0(6.1) A^{*}$ \\
\hline \multirow{6}{*}{$465 \mathrm{~A} \mathrm{~nm}$} & Estelite Sigma Quick & $56.0(6.5) \mathrm{A}$ & $54.6(5.4) \mathrm{A}$ \\
\hline & Charisma Classic & 70.0 (7.8) A & $68.0(6.8) \mathrm{A}$ \\
\hline & Filtek Z250 & $77.0(10.8) \mathrm{A}$ & $58.3(4.3) \mathrm{B}$ \\
\hline & Filtek Supreme Ultra & $73.0(7.4) \mathrm{A}$ & $76.2(2.1) \mathrm{A}$ \\
\hline & Tetric EvoCeram Bulk Fill & $55.8(3.5) \mathrm{A}$ & $58.3(4.3) \mathrm{A}$ \\
\hline & Filtek Bulk Fill Posterior & $69.4(7.6) \mathrm{A}$ & 70.8 (4.7) A \\
\hline
\end{tabular}

Means followed by different letters indicate a significant difference (uppercase letters compare treatment within the same RBC and wavelength; and * indicate significant difference comparing wavelengths for the same RBC and treatment) by two-way repeated-measures ANOVA and post-hoc Tukey's test $(\mathrm{p}<0.05)$.

\section{Surface roughness (Sa)}

Table 4 reports the Sa medians of both unbrushed and brushed areas of the RBCs. Toothbrushing did not affect surface roughness for Tetric EvoCeram Bulk Fill. However, it decreased the surface roughness of Filtek Z250, Filtek Supreme Ultra, and Filtek Bulk Fill Posterior. Charisma Classic presented a statistically significant increase in surface roughness following toothbrushing. At the unbrushed area, Filtek Bulk Fill Posterior showed the greatest roughness mean, while among toothbrushed areas, Charisma Classic presented the highest Sa mean compared to the other RBCs.

Table 4. Median (minimum and maximum) of surface roughness $(\mu \mathrm{m})$ before and after brushing.

\begin{tabular}{lcc}
\hline & Unbrushed & Brushed \\
\hline Estelite Sigma Quick & $1.5(1.2-1.9) \mathrm{Ab}$ & $1.1(0.5-1.7) \mathrm{Ab}$ \\
Charisma Classic & $1.6(1.6-2.2) \mathrm{Bb}$ & $2.1(1.7-2.3) \mathrm{Aa}$ \\
Filtek Z250 & $1.5(1.3-1.8) \mathrm{Ab}$ & $1.4(1.2-1.8) \mathrm{Bb}$ \\
Filtek Supreme Ultra & $1.8(1.6-1.9) \mathrm{Ab}$ & $1.4(1.3-1.7) \mathrm{Bb}$ \\
Tetric EvoCeram Bulk Fill & $1.7(1.4-1.8) \mathrm{Ab}$ & $1.0(0.6-1.8) \mathrm{Ab}$ \\
Filtek Bulk Fill Posterior & $2.0(1.6-3.6) \mathrm{Aa}$ & $1.5(0.8-2.0) \mathrm{Bb}$ \\
\hline
\end{tabular}

Mediane followed by different letters indicate a significant difference $(\mathrm{p}<0.05)$. Uppercase letters compare treatment within the same RBC by Wilcoxon signed-rank test. Lowercase letters compare RBC within the same treatment by Kruskal-Wallis and post-hoc Student-Newman-keuls. 


\section{Roughness profile (Rv) and volume loss}

The Rv and the volume loss medians of the RBCs are reported in Table 5. Following the same trend of Sa values, toothbrushing yielded the highest Rv median for Charisma Classic compared to the other RBCs $(p<0.05)$. No difference among RBCs was observed for the volume loss analysis $(p>0.05)$, although Charisma Classic presented greater variation of volume loss results.

Table 5. Median (minimum and maximum) of roughness profile $(\mu \mathrm{m})$ and volume loss $\times 10^{7}\left(\mu \mathrm{m}^{3}\right)$.

\begin{tabular}{lcc} 
& Roughness profile & Volume loss \\
\hline Estelite Sigma Quick & $2.1(1.1-4.5) \mathrm{b}$ & $2.0(1.1-3.3) \mathrm{a}$ \\
Charisma Classic & $3.3(2.1-3.5) \mathrm{a}$ & $2.8(0.4-6.5) \mathrm{a}$ \\
Filtek Z250 & $2.3(1.4-3.4) \mathrm{b}$ & $1.9(1.4-2.7) \mathrm{a}$ \\
Filtek Supreme Ultra & $1.8(1.6-2.8) \mathrm{b}$ & $1.7(1.4-2.5) \mathrm{a}$ \\
Tetric EvoCeram Bulk Fill & $2.4(2.0-3.5) \mathrm{b}$ & $2.0(1.6-3.5) \mathrm{a}$ \\
Filtek Bulk Fill Posterior & $2.2(1.2-2.5) \mathrm{b}$ & $2.4(1.5-3.2) \mathrm{a}$
\end{tabular}

Medians followed by different letters indicate a significant difference (lowercase letters compare RBC within the same analysis: Roughness profile or Volume loss) by Kruskal-Wallis and post-hoc Student-Newman-keuls ( $<<0.05)$.

\section{Gloss}

The gloss means of unbrushed and brushed areas are presented in Figure 3. Two-way mixed ANOVA showed that "composite", "toothbrushing", and the interaction between these factors significantly influenced gloss results $(p<0.001)$. Estelite Sigma Quick presented the highest gloss value for the unbrushed area. For the toothbrushed one, Filtek Supreme Ultra showed the greatest gloss retention. Charisma Classic and Filtek Z250 presented the lowest gloss values for both sides of the samples. Toothbrushing did not affect the gloss for Tetric EvoCeram Bulk Fill, and Filtek Supreme Ultra had an increase in GU following toothbrushing.

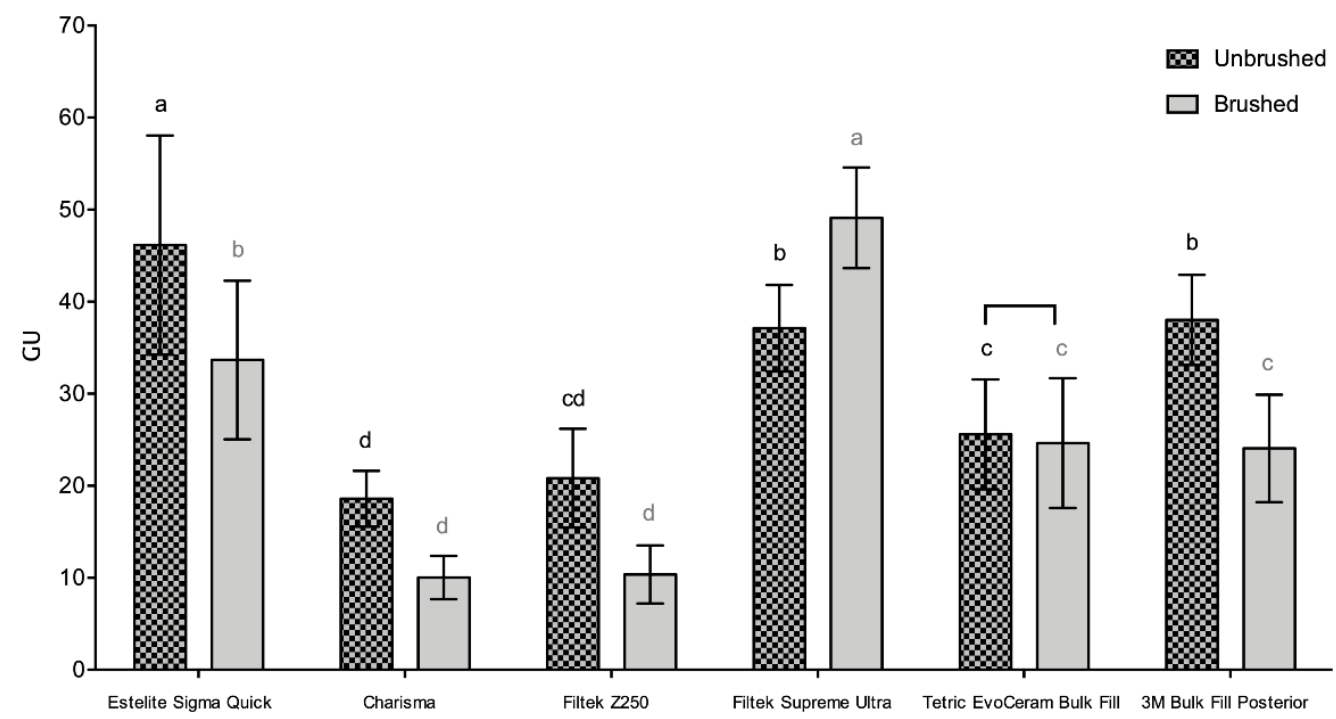

Figure 3. Gloss (GU) means (SD: error bars) of each RBCs for unbrushed and toothbrushed areas. Lowercase letters compare RBCs within the same treatment (unbrushed or toothbrushed). Connected bars indicate no statistically significant difference.

\section{Confocal images}

Figure 4 shows representative 2D confocal images of unbrushed and toothbrushed surfaces of the tested RBCs. The left side of each image corresponds to the area polished with 600-grit Al203 sandpaper, 
while the right side corresponds to the toothbrushed area. Scratches generated by the polishing procedure can be noticed at the unbrushed left sides of all images, which were removed following toothbrushing. Figure 5 shows representative 3D confocal images of unbrushed and toothbrushed surfaces of the tested RBCs. It is possible to notice a difference between the heights of the unbrushed and toothbrushed areas, showing the volume loss or wear after toothbrushing for all materials in 3D images. White spots were seen on the surface of Charisma Classic following toothbrushing (Figures 4B and $5 B$ ), corroborating with the significant increase in surface roughness after toothbrushing (Figures $4 \mathrm{~B}$ and $5 \mathrm{~B})$. For Tetric EvoCeram Bulk Fill, in which Sa was not affected by toothbrushing, visible scratches at both unbrushed and toothbrushed sides were detected (Figure 4E and $5 \mathrm{E}$ ).
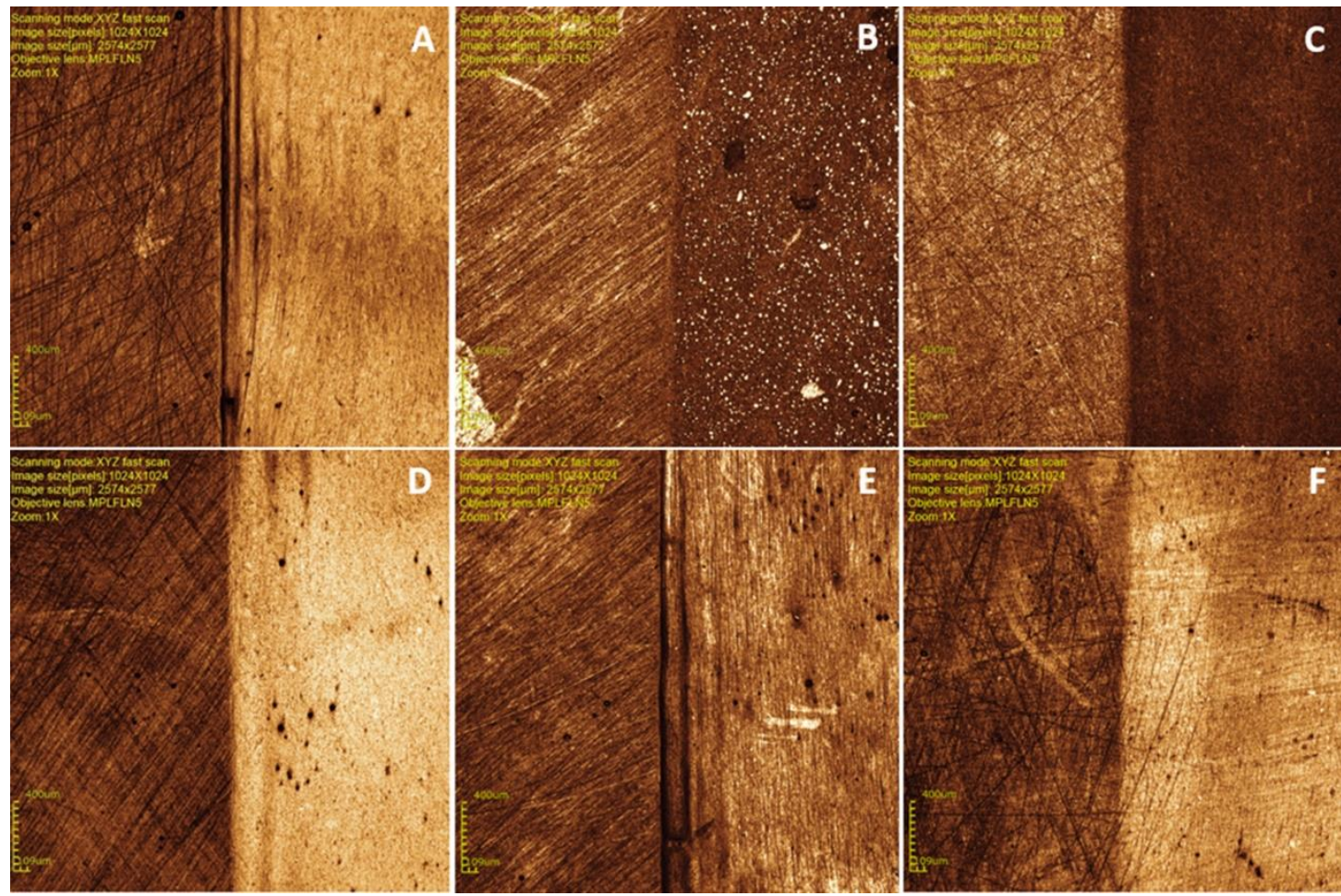

Figure 4. Two-dimensional confocal images showing the unbrushed (left side) and toothbrushed (right side) areas of RBCs. (A) Estelite Sigma Quick. (B) Charisma Classic. (C) Filtek Z250. (D) Filtek Supreme Ultra. (E) Tetric EvoCeram Bulk Fill. (F) Filtek Bulk Fill Posterior.

\section{Discussion}

There is a concern about multiple-peak LCUs regarding their ability to light-cure RBCs in a uniform manner, i.e., at the surface, inner part, and bottom of the restoration. A lack of homogeneity in light emission has been reported due to the positioning of LED chips (16), and it is one of the factors responsible for producing non-uniform curing (13). Therefore, this study tested a LED LCU that contains four LED chips and emits three wavelengths $(405,445$, and $465 \mathrm{~nm})$ regarding the surface uniform polymerization of RBCs. Additionally, the effects of toothbrushing wear on the areas of different irradiation were evaluated. No microhardness difference was obtained between $405 \mathrm{~nm}, 445 \mathrm{~nm}$, and $465 \mathrm{~nm}$ LEDs, regardless of the type of RBC, showing that homogeneity of light-emission by LED LCU has a limited effect on the polymerization of composite top surface $(13,17)$. This LCU features lens at its tip end that might favors the light beam homogenization. Therefore, the first null hypothesis stating that different wavelengths emitted by the LED LCU would not affect microhardness at different surface locations of the RBCs was accepted.

After toothbrushing, the microhardness of the $405 \mathrm{~nm}$-correspondent area did not differ from the $465 \mathrm{~A} \mathrm{~nm}$ wavelength for most composites, except for Filtek Bulk Fill Posterior at both sides (unbrushed and brushed) and Charisma Classic at the unbrushed side only. Although the microhardness of most of the tested composites remained statistically unchanged after toothbrushing, two distinct behaviors were observed: (I) microhardness decreased statistically for Filtek Z250 (21.8\%), while (II) microhardness significantly increased for Filtek Supreme Ultra (8.9\%) and Tetric EvoCeram Bulk Fill (8.9\%) at the 405 $\mathrm{nm}$ wavelength position. For $465 \mathrm{Anm}$, only one microhardness change was found, which was observed for Filtek Z250 (24.3\% reduction). In general, toothbrushing led to few changes in composite microhardness, regardless of the positioning of LED chips. The removal of the superficial layer and 
exposure of a sub-superficial layer (Figure 5) showed that most toothbrushed surface groups presented similar microhardness to their original unbrushed surfaces. However, the second hypothesis that simulated toothbrushing wear would not affect the microhardness of $405 \mathrm{~nm}$ wavelength position compared to $465 \mathrm{~nm}$ was rejected.
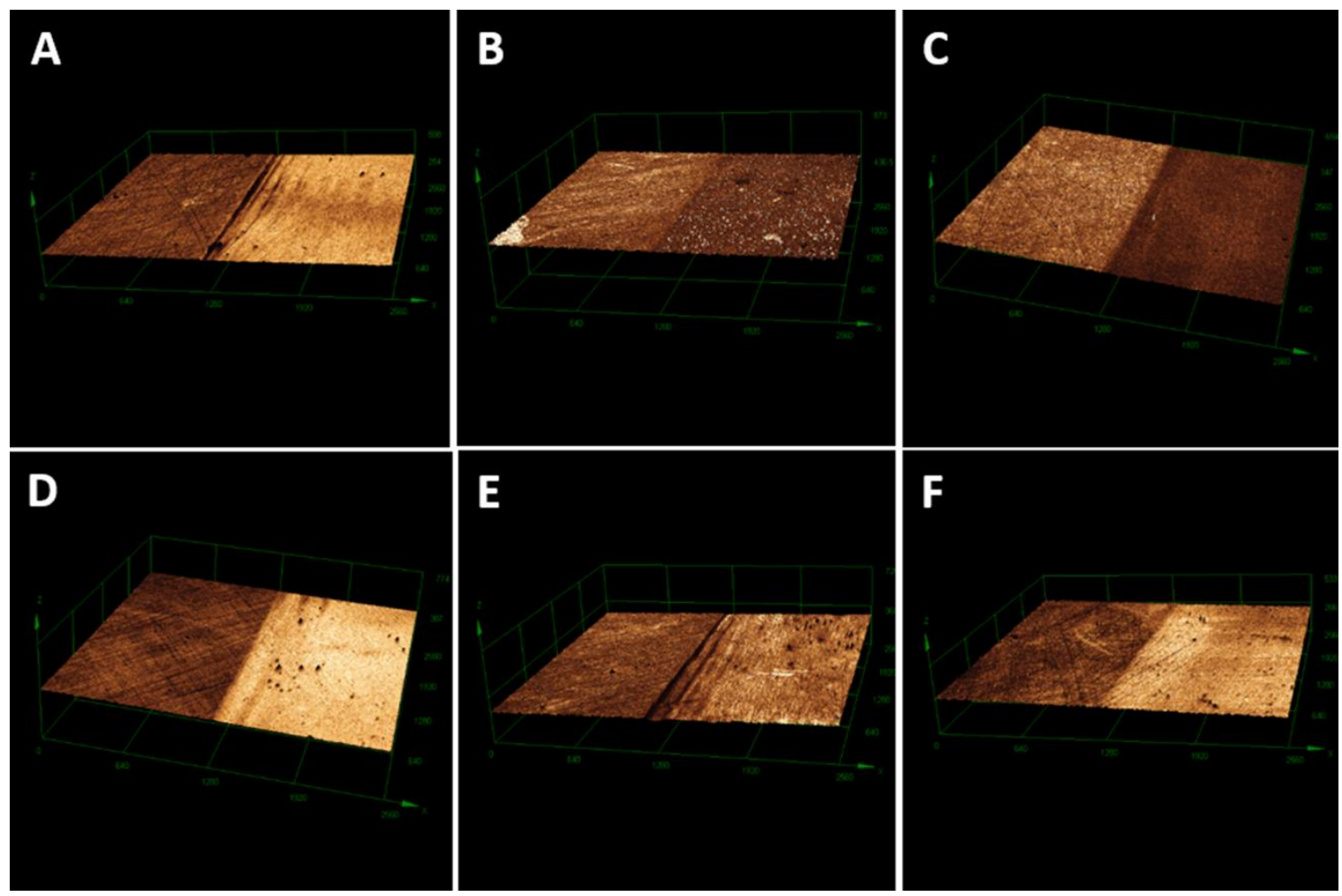

Figure 5. Three-dimensional confocal images showing the unbrushed (left side) and toothbrushed (right side) areas of RBCs. (A) Estelite Sigma Quick. (B) Charisma Classic. (C) Filtek Z250. (D) Filtek Supreme Ultra. (E) Tetric EvoCeram Bulk Fill. (F) Filtek Bulk Fill Posterior.

Toothbrushing increased the Sa mean only for Charisma Classic, which yielded the highest mean. Charisma Classic also showed the highest Rv among the tested RBCs, and the lowest gloss means at both sides (unbrushed and toothbrushed), with gloss reduction after toothbrushing. According to the confocal images, the toothbrushed surface of this composite presented white spots, which might represent large glass filler particles, around $10 \mu \mathrm{m}$ size, exposed at the surface. The increase of Sa was also due to the volume loss by the removal of the resin matrix, filler particles exposed on the surface that may create voids at the composite surface. On the other hand, toothbrushing reduced the Sa values for Filtek Z250, Filtek Supreme Ultra, and Filtek Bulk Fill Posterior, due to toothbrushing-induced attenuation of scratches that were created by 600 -grit $\mathrm{SiC}$ sandpaper polishing. These results were confirmed by the 2D and 3D confocal images (Figures 4C, 4D, and 4F). The size range of filler particles of these materials was smaller than Charisma Classic, which is a microhybrid RBC that presents filler particles from 0.005 to 10 $\mu \mathrm{m}$. Furthermore, the surface roughness can be affected by several factors related to the composite itself, such as type, shape, size, and distribution of filler particles, composition of the resin matrix, degree of conversion, and quality of the silane bonds at the filler/matrix interface (10). Thus, the third null hypothesis that toothbrushing would not affect the Sa and Rv of the tested RBCs was rejected.

On the other hand, the volume loss did not vary, regardless of the distinct organic and inorganic compositions of the tested RBCs. Thus, the fourth null hypothesis was accepted. Composites that have smaller filler particles may present a smoother surface after toothbrushing in comparison to the composites that have larger particles (18). Furthermore, the use of nanoparticles, as in Filtek Supreme Ultra and Filtek Bulk Fill, reduces the inter-particle spacing of composites, which can help protect the softer resin matrix from abrasive wear (19), reducing the detrimental effect of toothbrushing on surface roughness. Also, since all RBCs presented similar volume losses, one could imply lower microhardness values did not yield increased volume loss.

Even though some studies report that surface roughness is a critical factor in biofilm accumulation (20), another study showed surface topography could be considered more critical for the growth of 
Streptococcus mutans biofilms, as deeper and larger depressions may be more favorable to bacterial colonization (19). Another factor analyzed in the study was the Rv parameter, which can be defined as the arithmetic mean between peaks and valleys given by the movement of the confocal laser over a predetermined surface area (21). The highest Rv value was found for Charisma Classic, suggesting that this composite may be more prone to bacterial colonization compared to the other tested RBCs.

Surface gloss can be affected by filler particle size, chemical heterogeneity, and surface defects of RBCs (22). Four of the tested RBCs, Estelite Sigma Quick, Charisma Classic, Filtek Z250, and Filtek Bulk Fill Posterior, had a decrease in gloss mean values after toothbrushing, rejecting the fifth null hyphotesis. The only RBC among the ones used in the present study that is designated exclusively for posterior, loadbearing regions is Filtek Bulk Fill Posterior. Hence, the other RBCs are indicated for both posterior and anterior restorations, according to their manufacturers. The lack of gloss retention for anterior restorations may compromise their esthetics, an important factor for the longevity of this type of restorative procedure (23). Filtek Supreme Ultra exhibited an increase of gloss after toothbrushing. This RBC is classified as a nanofilled composite, and it may better retain polish over time compared to other RBCs (20). Therefore, the toothbrushing protocol might have acted as polishing for this composite, justifying the increase in surface gloss and the decrease in Sa. Filtek Bulk Fill Posterior, Filtek Z250, and Estelite Sigma Quick RBCs showed a reduction in gloss means after toothbrushing. However, they did not lead to an increase in surface roughness.

Tetric EvoCeram Bulk Fill showed no difference in Sa mean values and retained the gloss after toothbrushing. This composite is classified as nanohybrid and has camphorquinone and Ivocerin photoinitiators, which requires light-curing by the blue and violet wavelengths $(13,25)$. The LCU used in this study ( $\mathrm{Valo}$ ) is a multiple-peak LCU containing a violet $405 \mathrm{~nm}$ emission peak, indicated to lightcure this RBC. Besides stable results for Sa and gloss after toothbrushing, no difference was observed for the volume loss of Tetric EvoCeram Bulk Fill compared to the other RBCs, and a lower Rv value compared to Charisma Classic was obtained. Gloss units for Tetric EvoCeram Bulk Fill were lower than those achieved by Estelite Sigma Quick, Filtek Supreme Ultra, and Filtek Bulk Fill Posterior.

In conclusion, different LED wavelengths emitted by light-curing units had little effect on the surface microhardness of the tested RBCs, showing the light homogeneity emitted by LED LCU used. However, after toothbrushing the violet $405 \mathrm{~nm}$ LED irradiation position presented lower surface microhardness than that obtained at 465A nm for two RBCs. Charisma Classic was the most affected by toothbrushing compared to the other RBCs, exhibiting the greatest surface roughness and roughness profile means, as well as a decrease in gloss after toothbrushing. Bulk-fill composites presented the same behavior when compared to conventional composites after toothbrushing regarding volume loss; and similar behavior regarding roughness and roughness profile, except when compared to Charisma Classic.

\section{Acknowledgements}

This study was supported by the Institutional Program for Scientific Initiation Scholarships of UNICAMP (PIBIC-CNPq) and National Council for Scientific and Technological Development (423389/2018-1), Brazil.

\section{Resumo}

Este estudo in vitro avaliou a homogeneidade do feixe de um fotopolimerizador de múltiplos picos na microdureza superficial e o efeito da escovação na microdureza, rugosidade superficial, perfil de rugosidade, perda de volume e retenção do brilho de compósitos a base de resina (RBCs) incrementais ou bulk-fill. Um fotopolimerizador LED (VALO) com quatro LEDs na ponteira $(405,445,465 \mathrm{~A}$ e $465 \mathrm{Bm}$ de pico de emissão) foi usado de acordo com o tempo recomendado por cada fabricante para obtenção de discos $(n=10)$ de seis RBCs: Estelite Sigma Quick, Charisma Classic, Tetric EvoCeram Bulk Fill, Filtek Z250, Filtek Supreme Ultra e Filtek Bulk Fill. Os valores de microdureza foram obtidos seguindo o posicionamento de cada LED na superfície superior das amostras e foram analisados antes e após a escovação quanto a microdureza, rugosidade superficial, perfil de rugosidade, perda de volume e retenção do brilho. A microdureza foi considerada homogênea no topo da superfície, independentemente do tipo de RBCs ou comprimento de onda testados ( $p>0.05)$. No geral, a escovação não reduziu a microdureza das RBCs, mas influenciou o brilho para a maioria das RBCs $(p<0.001)$. Charisma Classic apresentou os maiores valores de rugosidade superficial e perfil de rugosidade após a escovação $(p<0.05)$. A perda de volume não diferiu entre as RBCs ( $p>0.05$ ). Em conclusão, os diferentes comprimentos de onda do LED não alteraram a microdureza do topo da superficie, independentemente das RBCs testadas; 
e as resinas bulk-fill apresentaram alterações superficiais similares (microdureza, rugosidade superficial, perfil de rugosidade, perda de volume e manutenção do brilho) quando comparadas às resinas convencionais após a escovação. 


\section{References}

1. Fronza BM, Rueggeberg FA, Braga RR, Mogilevych B, Soares LE, Martin AA, et al. Monomer conversion, microhardness, internal marginal adaptation, and shrinkage stress of bulk-fill resin composites. Dent Mater 2015; 31: 1542-1551.

2. Demarco FF, Collares K, Correa MB, Cenci MS, Moraes RR, Opdam NJ. Should my composite restorations last forever? Why are they failing? Braz Oral Res 2017; 31: e56.

3. Laske M, Opdam NJ, Bronkhorst EM, Braspenning JC, Huysmans MC. Longevity of direct restorations in Dutch dental practices. Descriptive study out of a practice based research network. J Dent 2016; 46: 12-17.

4. Hurst D. Amalgam or composite fillings--which material lasts longer? Evid Based Dent 2014; 15: 50-51.

5. Huang $B$, Siqueira WL, Cvitkovitch $D G$, Finer $Y$. Esterase from a cariogenic bacterium hydrolyzes dental resins. Acta Biomater 2018; 71: 330-338.

6. Badra VV, Faraoni JJ, Ramos RP, Palma-Dibb RG. Influence of different beverages on the microhardness and surface roughness of resin composites. Oper Dent 2005; 30: 213-219.

7. Krämer N, Reinelt $C$, Frankenberger R. Ten-year Clinical Performance of Posterior Resin Composite Restorations. J Adhes Dent 2015; 17: 433-441.

8. Salgado VE, Cavalcante LM, Moraes RR, Davis HB, Ferracane JL, Schneider LF. Degradation of optical and surface properties of resin-based composites with distinct nanoparticle sizes but equivalent surface area. J Dent 2017; 59: 48-53.

9. Ardu S, Daher R, Di Bella E, Rossier I, Krejci I. Influence of mechanical and chemical degradation on surface gloss of direct and CAD-CAM resin composite materials. Am J Dent 2020; 33: 157-160.

10. Ilie N, Hilton TJ, Heintze SD, Hickel R, Watts DC, Silikas N, et al. Academy of Dental Materials guidance-Resin composites: Part I-Mechanical properties. Dent Mater 2017; 33: 880-894.

11. Harrington $E_{1}$, Jones $P A$, Fisher $S E$, Wilson HJ. Toothbrush-dentifrice abrasion. A suggested standard method. Br Dent J 1982; 153: 135-138.

12. Sahadi BO, Price RB, André CB, Sebold M, Bermejo GN, Palma-Dibb RG, Faraoni JJ, Soares CJ, Giannini M. Multiple-peak and single-peak dental curing lights comparison on the wear resistance of bulk-fill composites. Braz Oral Res 2018; 32: 122.

13. Soto-Montero J, Nima G, Rueggeberg FA, Dias C, Giannini M. Influence of Multiple Peak Lightemitting-diode Curing Unit Beam Homogenization Tips on Microhardness of Resin Composites. Oper Dent 2020; 45: 327-338.

14. Macgregor ID, Rugg-Gunn AJ. Toothbrushing duration in 60 uninstructed young adults. Community Dent Oral Epidemiol 1985; 13: 121-122.

15. Sturz CR, Faber FJ, Scheer M, Rothamel D, Neugebauer J. Effects of various chair-side surface treatment methods on dental restorative materials with respect to contact angles and surface roughness. Dent Mater J 2015; 34: 796-813.

16. Michaud PL, Price RB, Labrie $D$, Rueggeberg FA, Sullivan B. Localised irradiance distribution found in dental light curing units. J Dent 2014; 42: 129-139.

17. Shimokawa $C$, Turbino ML, Giannini M, Braga RR, Price RB. Effect of Curing Light and Exposure Time on the Polymerization of Bulk-Fill Resin-Based Composites in Molar Teeth. Oper Dent 2020; 45: E141-E155.

18. Salgado VE, Cavalcante LM, Silikas N, Schneider LF. The influence of nanoscale inorganic content over optical and surface properties of model composites. J Dent 2013; 41: 45-53.

19. Lim BS, Ferracane JL, Condon JR, Adey JD. Effect of filler fraction and filler surface treatment on wear of microfilled composites. Dent Mater 2002; 18: 1-11.

20. Shimokawa C, Giannini M, André CB, Sahadi BO, Faraoni JJ, Palma-Dibb RG, et al. In vitro evaluation of surface properties and wear resistance of conventional and bulk-fill resin-based composites after brushing with a dentifrice. Oper Dent 2019; 44: 637-647.

21. Park JW, Song CW, Jung JH, Ahn SJ, Ferracane JL. The effects of surface roughness of composite resin on biofilm formation of Streptococcus mutans in the presence of saliva. Oper Dent 2012; 37: 532539.

22. Ereifej NS, Oweis $Y G$, Eliades $G$. The effect of polishing technique on 3-D surface roughness and gloss of dental restorative resin composites. Oper Dent 2013; 38: 1-12.

23. Jassé FF, de Campos EA, Lefever D, Di Bella E, Salomon JP, Krejci I, et al. Influence of filler charge on gloss of composite materials before and after in vitro toothbrushing. J Dent 2013; 41: 41-44. 
24. Gan JK, Yap AU, Cheong JW, Arista N, Tan C. Bulk-Fill Composites: Effectiveness of cure with poly- and monowave curing lights and modes. Oper Dent 2018; 43: 136-143. 